\title{
THEORETICAL APPROACH ON THE STUDY OF TURBULENT WATER FLOW OVER SMOOTH AND L-SHAPED RIBLETS SURFACES
}

\author{
A. BRIMA ${ }^{1}$, R. ATMANI' AND B. ACHOUR ${ }^{2}$ \\ ${ }^{1}$ Department of Mechanics, University of Biskra, Algeria \\ Research laboratory in Mechanical Engineering (LGM) \\ ${ }^{2}$ Department of Hydraulics, University of Biskra, Algeria \\ Research laboratory in Subterranean and surface Hydraulics (LARHYSS) \\ E-mail: hafiddd@hotmail.com
}

\begin{abstract}
A very important research effort has been developed at many world laboratories these last years in order to reduce the friction drag. For the aircraft and the submarine applications, friction contributes respectively for about $50 \%$ and $70 \%$ of the total resistance. The use of surface modifications riblets as a means of reducing viscous drag on a body has potential aerodynamic and hydrodynamic applications. In the present study, the theoretical approach allow to determine the velocity field, the wall shear stress, the local skin friction, the boundary layer thickness, the laminar sub layer thickness and the dimensionless drag coefficient. The results found, indicate that the presence of L-shaped riblets surfaces provide changes in the characteristics of the turbulent boundary layer, which are in favor of wall skin friction.
\end{abstract}

KEYWORDS: turbulent flow, riblets, shear stress, layer thickness, friction reduction.

\begin{abstract}
RESUME
Un effort très important a été fourni ces dernières années à travers les laboratoires du monde dans le domaine de la réduction de traînée visqueuse. Pour les avions de transport et les sous marins, la traînée visqueuse contribue respectivement d'environ $50 \%$ à $70 \%$ de la résistance totale. L'utilisation des modifications au niveau de la surface est un moyen efficace pour réduire la traînée visqueuse dans les applications aérodynamique et hydrodynamique. Dans cette étude, l'approche théorique permis de déterminer le champ de vitesse, la contrainte de cisaillement à la paroi, le coefficient de frottement local, l'épaisseur de la couche limite, l'épaisseur de la sous couche visqueuse et finalement le coefficient non dimensionnel de traînée sont représentés. Les résultats trouvés ont montré que la présence des rainures en lames " L " fournie des changements dans les caractéristiques de la couche limite turbulente, qui sont en faveur du coefficient de frottement pariétal.
\end{abstract}

MOTS CLES : écoulement turbulent, riblets, contrainte de cisaillement, épaisseur de couche, réduction de frottement.

\section{INTRODUCTION}

The first researchers who presented the results about the reduction of parietal friction were (Walsh and Weinstein, 1978) [1].They managed to modify the wall geometry by using the longitudinal grooves in a triangular form, called "Riblets". The obtained results indicated the reduction of the friction in about $8 \%$ in comparison with the smooth surface. This geometrical modification of the wall is inspired from the observations on marine animals, "the sharks" (Chernyshov and Zayets, 1970) [2]. Some sharks skins show the existence of longitudinal and cross-section micro-structures that facilitate a remarkable mobility of the animal. Just after the first results, a chaining-up of theoretical and experimental studies took part in different scientific places in the world. The researchers varied the geometrical characteristics of the grooves, hoping to understand the riblets effects on the turbulent flow. Liu, Christodoulou, Reccius and Joseph, 1990 [3] were interested in the reduction of the friction drag in the turbulent flow in circular grooved conduct. Vugoslavecevic, Wallace and Balint, 1992 [4] found the results which indicate the longitudinal shear stress in the level of the picks increase in about $85 \%$ in comparison with the smooth case. The direct numerical study D.N.S carried on by Choi, Moin and Kim, 1993 [5] demonstrated that the results of the fluctuated field precise a neat reduction of the three fluctuating components of the velocity in comparison 
to the smooth surface. The structure of the turbulence on riblets surfaces compared to that of a flat plate has been analyzed by Benhalilou, Anselmet and Fulachier, 1994 [6]. The latter have demonstrated that the contributions of the production of the Reynolds tension from the ejections and the sweepings are larger and more frequent on the riblets than on the smooth case. These contributions are reduced inside the riblets. The structure of the turbulence of the near wall is different when the riblets reduce or increase the friction drag in comparison to the smooth surface. This observation was carried by Djenidi and Antonia, 1996 [7]. The authors note that the turbulent field is more sensible with the presence of the riblets surfaces than the mean field. With an extreme relative precision, (Dubief, Djenidi and Antonia, 1997) [8] have measured, the gradient statistics of the longitudinal fluctuating component $\mathrm{du}^{\prime} / \mathrm{dy}$ using a parallel hot wire. The obtained results of the riblets in the case of the drag reduction indicate that the variance of the gradient (normalized by the use of the wall variables) is weaker on the smooth plate. This difference increases when the normal distance of the wall decreases. The riblets in two-dimensional fins are of higher performance in the reduction of the drag friction domain in comparison with the three-dimensional ones. This was confirmed by Bechert, Bruse and Hage, 2000 [9] as a result of study realized in the interval $10^{4} \leq R_{h} \leq 3 \times 10^{4}$ of a number of Reynolds numerated to the height of the channel. Concerning the structure of turbulent boundary layer near the wall, Lee and Lee, 2001 [10] remarked that in case of the drag reduction, the size of the stream wise vortices is very large in comparison to the spacing of the riblets. This is what makes the flow inside the riblets relatively calm. In a very detailed paper (Coustols, 2001) [11] have presented a synthesis of the experimental studies carried on at the ONERA and in the world during last years in order to enrich the significant effects attributed to the presence of those riblets in the flow. The angle of damage between the stream lines and the orientation of the riblets was subject to an experimental study realized by Viswanath, 2002 [12]. The author concluded that the damaged angles superior to $15^{\circ}$ have an important damage of the riblets performances. The temperature effect on the characteristics of the turbulent flow, above the grooved surfaces, was highlighted by Stalio and Nobile, 2003 [13]. The authors demonstrated very clearly that the heat transfer effect is less important on the riblets surfaces than on the smooth one for Prandtl number equal to 0.71 . In our study, we choose the L-shaped riblets surfaces represented in Fig.1.This geometric surface is one of the forms quoted by Brima and Atmani, 2004 [14].

\section{DEFINITION \\ AND RIBLETS PERFORMANCES}

Riblets are groove surfaces in the same direction of the flow which have been originally developed by (NASA Langley Research Center) at the end of the last century in order to reduce the turbulent friction. One can also define them as the thin ribs placed longitudinally on the wall, as the corduroy. Riblets are characterized by two essential geometric parameters, namely riblets spacing (s) and riblets height (h) (see Fig .1). The first practical use of riblets was made by the U.S men's rowing boat at the Los-Angeles Olympic Games in 1984.Riblets was also used by stars in order to win the American's cup in 1987. In the Sidney Olympic Games in 2000 top swimmers used swimming suits with riblets to win many gold medals.

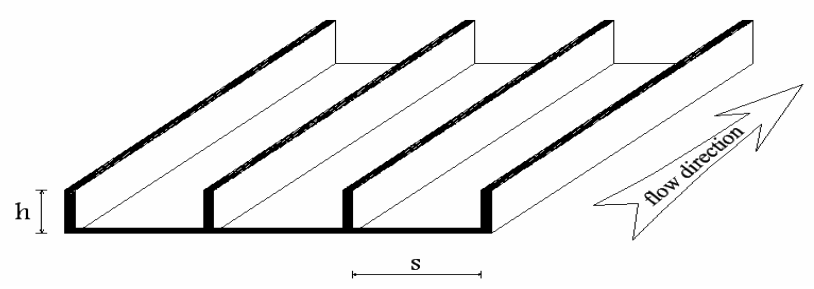

Figure 1 : L-shaped riblets geometries.

\section{THEORETICAL APPROACH}

In order to understand the behavior of the turbulent boundary layer flow, semi empirical expressions are used.Turbulent boundary layer data over a wide range of Reynolds number are well correlated with the Prandtl one seventh root velocity profiles (Janna, 1994) [15]. The velocity profile through the boundary layer being defined by:

$$
U_{x} / U_{\infty}=(y / \delta)^{1 / 7}
$$

Where $U_{x}$ is the velocity at any height " $\mathrm{y}$ " above the surface, $U_{\infty}$ is the free stream velocity and the parameter $\delta$ is the boundary layer thickness. Equation (1) is represented in Fig.3, showing the variation of $U_{x} / U_{\infty}=(y / \delta)$. Concerning the expression of the wall shear stress, it is defined by Hollman, 1992 [16] with respect of the Reynolds number limit $\mathrm{Re}_{x}<10^{7}$.

$$
\tau_{w}=0.029 \rho U_{\infty}^{2}\left(v / U_{\infty} x\right)^{1 / 5}
$$

Where $v$ is the fluid kenematic viscosity and $\rho$ is the fluid density and $x$ is the position just after the leading edge until the end of the length of the plane.

Where the local skin friction $C_{f}$ represented in Fig. 9, is defined by:

$$
C_{f}=2 \tau_{w} /\left(\rho U_{\infty}^{2}\right)
$$

Also, the total drag force on the plate is determined by integrating the wall shear stress over the surface area of the plate of length $\ell$ and becomes (Janna, 1994) [15].

$$
D=b \int_{0}^{\ell} \tau_{w} d x=0.0358 \rho U_{\infty}^{2} b \ell /\left(\mathrm{Re}_{\ell}\right)
$$

Where $b$ is the test plate width, $\ell$ is the test plate length and $\operatorname{Re}_{\ell}$ is the dimensionless Reynolds number based on the test plate total length. 
The drag coefficient represented in Fig.10, is given by Janna, 1994 [15] as:

$$
C_{D}=0.074 /\left(\mathrm{Re}_{\ell}\right)^{1 / 5}
$$

The boundary layer thickness $\delta$ reported in Tables 1 and 2 is obtained by the same authors as:

$$
\delta=0.368 . x /\left(\operatorname{Re}_{x}\right)^{1 / 5}
$$

Where $\operatorname{Re}_{x}$ is the dimensionless Reynolds number at any distance $x$ from the leading edge.

The laminar sub layer thickness $\delta_{L}$ given in Tables was evaluated using (Schlichting's, 1979) [17] equation as:

$$
\delta_{L} \approx 5 v /\left(\tau_{W} / \rho\right)^{1 / 2} \approx 5 v / U_{\tau}
$$

The friction velocity which depends on the shear stress on the flat surface and the fluid density is obtained by the use of equation:

$$
U_{\tau}=\left(\tau_{W} / \rho\right)^{1 / 2}
$$

Let us consider a test plate with dimension $b \times \ell=0.2 \mathrm{~m}^{2}$ and a water free stream velocity of $0.2(\mathrm{~m} / \mathrm{s})$ at $20^{\circ} \mathrm{C}$. The geometric characteristics of the used riblets shape (see Fig.1) are $s=2 \times h=2 \times 10^{-3}(\mathrm{~m})$. At each position $\mathrm{x}$ along the inner wall of the fictitious water channel represented in Fig.2, the boundary layer characteristics for the smooth plane has been computed using equations (2),(3),(6),(7) and (8) and reported in Table.1.

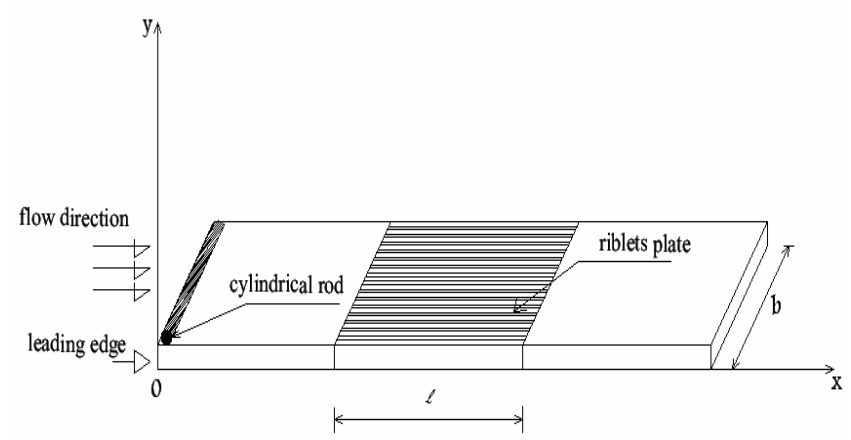

Figure 2: Definition sketch of the theoretical model.

Total drag along the inner wall can be computed by the use of equation (4). For the surface dimension $\mathrm{b} \times \ell=0.2 \mathrm{~m}^{2}$, the result is $\mathrm{D}=0.02493(\mathrm{~N})$. The wall shear stress for the riblets surfaces was given by the following equation:

$$
\tau_{w}=C \cdot \rho U_{\infty}^{2}\left(v / U_{\infty} x\right)^{1 / 5}
$$

The percent of viscous drag reduction is given by: $\frac{\tau_{w}(\text { smooth })-\tau_{w}(\text { riblets })}{\tau_{w}(\text { smooth })}(\%)$.

When the maximum of reduction for the L-shaped riblets is around $10 \%$, we can numerate the constant $\mathrm{C}$ with respect of the following steps:

- Choose the value of percent drag.

- Replace each wall shear stress with its expression.

- Find easily the constant $\mathrm{C}$.

After the compute of the wall shear stress values at each position along the riblets surfaces by the use of equation (9), the corresponding boundary layer characteristics has been evaluated using equations (3), (6),(7) and (8) and reported in Table 2.

\section{RESULTS}

Fig.3 shows the variation of dimensionless velocity from the wall to the maximum boundary layer thickness. Using selected points along the two shaped surfaces, the theoretical boundary layer characteristics are computed and reported in Tables 1 and 2 . The boundary layer parameters for each plate can be linked to both the Reynolds number $R_{e}$ and the position $x$. Using table 1 and $2, U^{+}$and $Y^{+}$ were computed for the several $y$ positions as: $Y^{+}=\frac{U_{\tau}}{v} y$, $U^{+}=\frac{U_{\infty}}{U_{\tau}}\left(\frac{y}{\delta}\right)^{1 / 7}$. Values of $U^{+}$and $Y^{+}$were plotted in Fig. 4 to 7 with the respect of the Logarithm laws. Fig. 8 shows the variation of the friction velocity along the inner wall of the channel previously defined in Fig.2. The variation of the local skin friction downstream the leading edge and the end of the plate is shown in Fig.9. The drag coefficient is plotted in Fig. 10 as a function of the Reynolds number based on the total length of the plate.

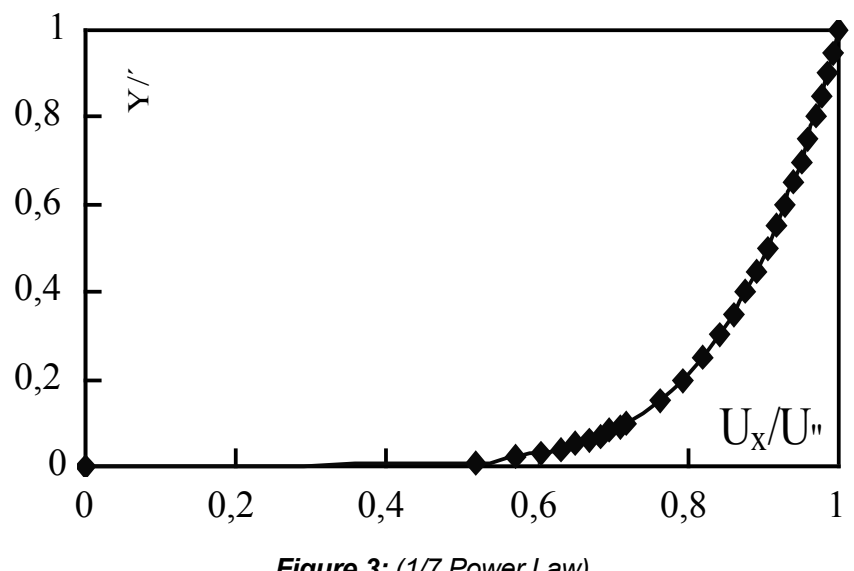

Figure 3: (1/7 Power Law) 
Table 1: Theoretical boundary layer characteristics for the smooth plane.

\begin{tabular}{|c|c|c|c|c|c|c|}
\hline $\mathrm{X}(\mathrm{m})$ & $\tau\left(N / \mathrm{m}^{2}\right)$ & $\mathrm{C}_{\mathrm{f}}$ & $\mathrm{R}_{\mathrm{e}}$ & $\mathrm{U}_{\tau}(\mathrm{m} / \mathrm{s})$ & $\delta \times 10^{3}(\mathrm{~m})$ & $\delta_{\mathrm{L}} \times 10^{3}(\mathrm{~m})$ \\
\hline 0.05 & 0,1838 & 0,009192 & $1.10^{4}$ & 0.01355 & 02.91 & 0.369 \\
\hline 0.10 & 0,1600 & 0,008002 & $2.10^{4}$ & 0.01265 & 05.07 & 0.395 \\
\hline 0.20 & 0,1393 & 0,006966 & $4.10^{4}$ & 0.01180 & 08.84 & 12.22 \\
\hline 0.30 & 0,1284 & 0,006423 & $6.10^{4}$ & 0.01133 & 15.39 & 0,423 \\
\hline 0.40 & 0,1212 & 0,006064 & $8.10^{4}$ & 0.01101 & 18.40 & 0,454 \\
\hline 0.50 & 0.1159 & 0.005795 & $1.10^{5}$ & 0.01076 & 21.28 & 0.464 \\
\hline 0.60 & 0.1117 & 0.005585 & $1.2 .10^{5}$ & 0.01056 & 24.08 & 0.472 \\
\hline 0.70 & 0.1083 & 0.005419 & $1.4 .10^{5}$ & 0.01041 & 26.79 & 0.480 \\
\hline 0.80 & 0.1055 & 0.005275 & $1.6 .10^{5}$ & 0.01027 & 0.486 \\
\hline 0.90 & 0.1030 & 0.005150 & $1.8 .10^{5}$ & 0.01014 & 29.44 & 0.492 \\
\hline 1.00 & 0.1009 & 0.005045 & $2.10^{5}$ & 0.01004 & 32.03 & 0.497 \\
\hline
\end{tabular}

Table 2. Theoretical boundary layer characteristics for the riblets surfaces.

\begin{tabular}{|c|c|c|c|c|c|c|}
\hline $\mathrm{x}(\mathrm{m})$ & $\tau\left(\mathrm{N} / \mathrm{m}^{2}\right)$ & $\mathrm{C}_{\mathrm{f}}$ & $\mathrm{R}_{\mathrm{e}}$ & $\mathrm{U}_{\tau}(\mathrm{m} / \mathrm{s})$ & $\delta \times 10^{3}(\mathrm{~m})$ & $\delta_{\mathrm{L}} \times 10^{3}(\mathrm{~m})$ \\
\hline 0.05 & 0,1755 & 0.008775 & $1.10^{4}$ & 0.013247 & 02.77 & 0.377 \\
\hline 0.10 & 0,1504 & 0.007520 & $2.10^{4}$ & 0.012263 & 04.82 & 0.407 \\
\hline 0.20 & 0.1295 & 0.006475 & $4.10^{4}$ & 0.011379 & 08.40 & 0.439 \\
\hline 0.30 & 0.1187 & 0.005935 & $6.10^{4}$ & 0.010894 & 11.63 & 0.458 \\
\hline 0.40 & 0.1121 & 0.005605 & $8.10^{4}$ & 0.010587 & 14.64 & 0.472 \\
\hline 0.50 & $\mathbf{0 . 1 0 6 0}$ & 0.005300 & $1.10^{5}$ & $\mathbf{0 . 0 1 0 2 9 5}$ & $\mathbf{1 7 . 5 0}$ & 0.485 \\
\hline 0.60 & $\mathbf{0 . 1 0 0 5}$ & 0.005025 & $1.2 .10^{5}$ & $\mathbf{0 . 0 1 0 0 2 4}$ & $\mathbf{2 0 . 2 5}$ & $\mathbf{0 . 4 9 8}$ \\
\hline 0.70 & 0.0969 & 0.004845 & $1.4 .10^{5}$ & 0.009843 & $\mathbf{2 2 . 9 0}$ & $\boldsymbol{0 . 5 0 7}$ \\
\hline 0.80 & 0.0938 & 0.004690 & $1.6 .10^{5}$ & 0.009685 & $\mathbf{2 5 . 4 9}$ & $\boldsymbol{0 . 5 1 6}$ \\
\hline 0.90 & 0.0911 & 0.004555 & $1.8 .10^{5}$ & 0.009544 & 28.00 & $\mathbf{0 . 5 2 4}$ \\
\hline 1.00 & 0.0892 & 0.004460 & $2.10^{5}$ & 0.009444 & $\mathbf{3 0 . 4 7}$ & 0.529 \\
\hline
\end{tabular}

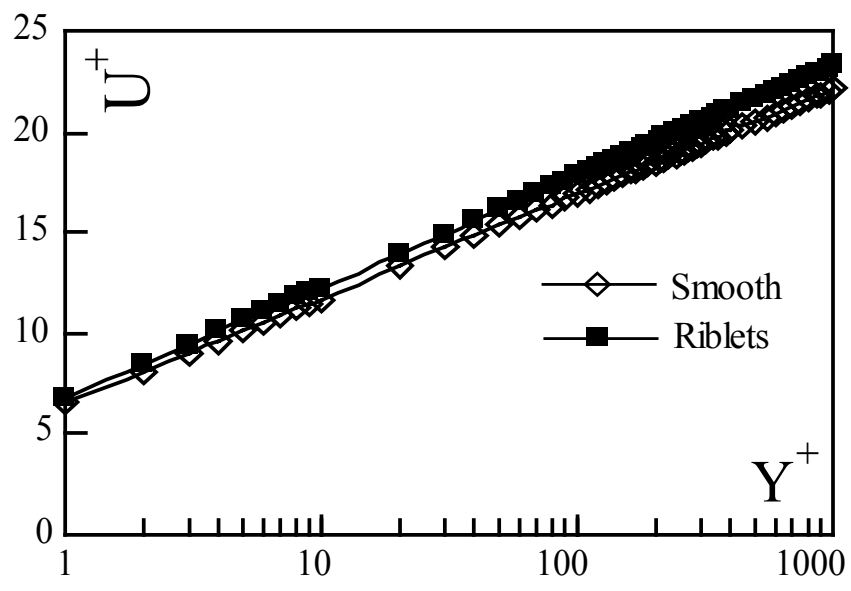

Figure 4. Variation of $U^{+}\left(Y^{+}\right)$at $x=300 \mathrm{~mm}$

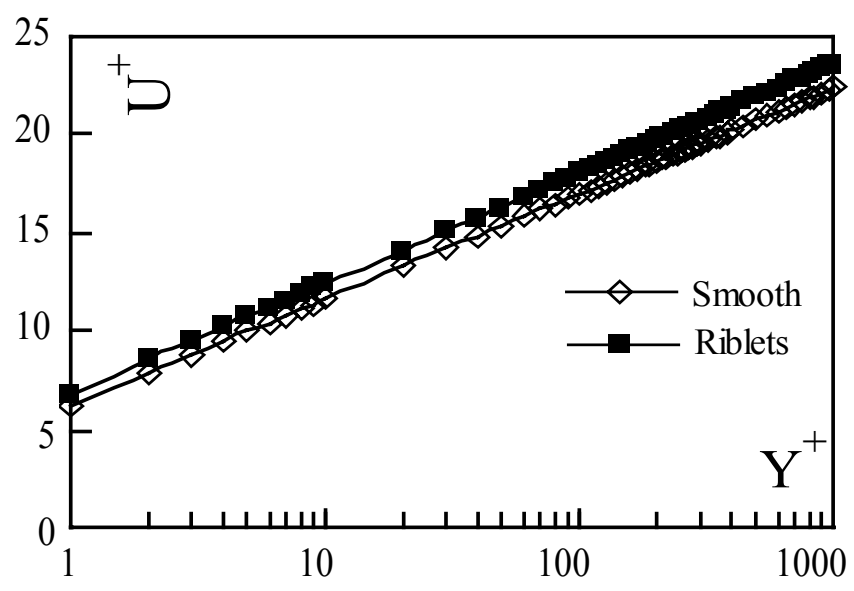

Figure 5. Variation of $U^{+}\left(Y^{+}\right)$at $x=500 \mathrm{~mm}$ 


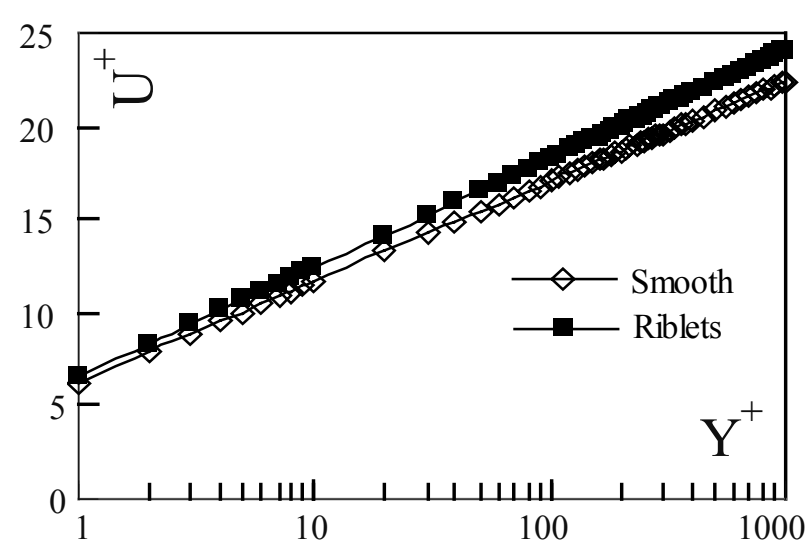

Figure 6. Variation of $U^{+}\left(Y^{+}\right)$at $x=700 \mathrm{~mm}$

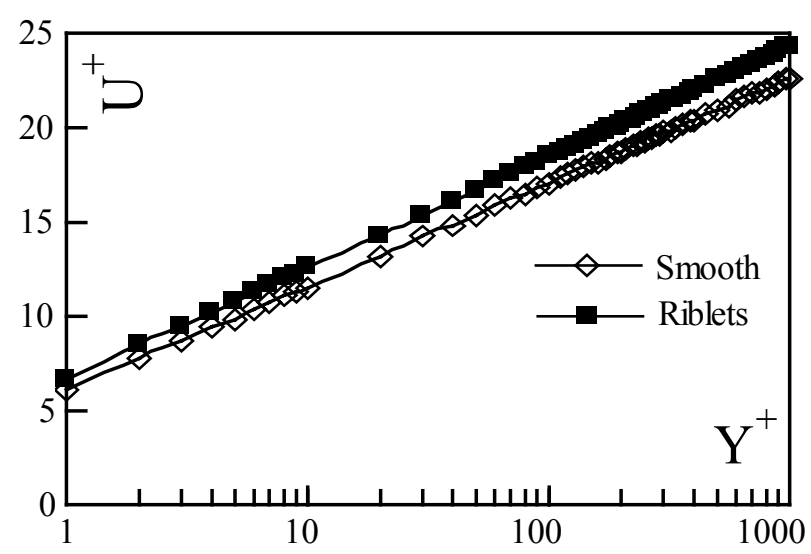

Figure 7. Variation of $U^{+}\left(Y^{+}\right)$at $x=900 \mathrm{~mm}$

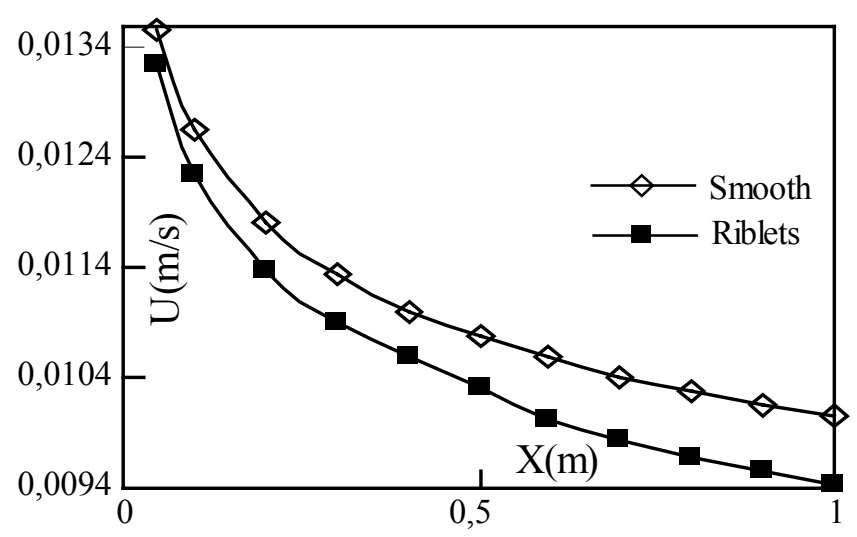

Figure 8. Variation of $U \tau(X)$

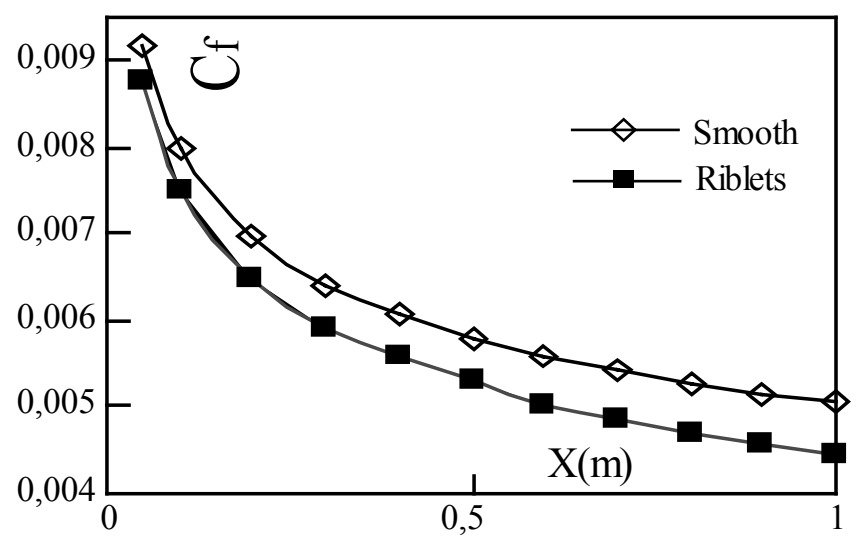

Figure 9. Variation of $C_{f}(X)$

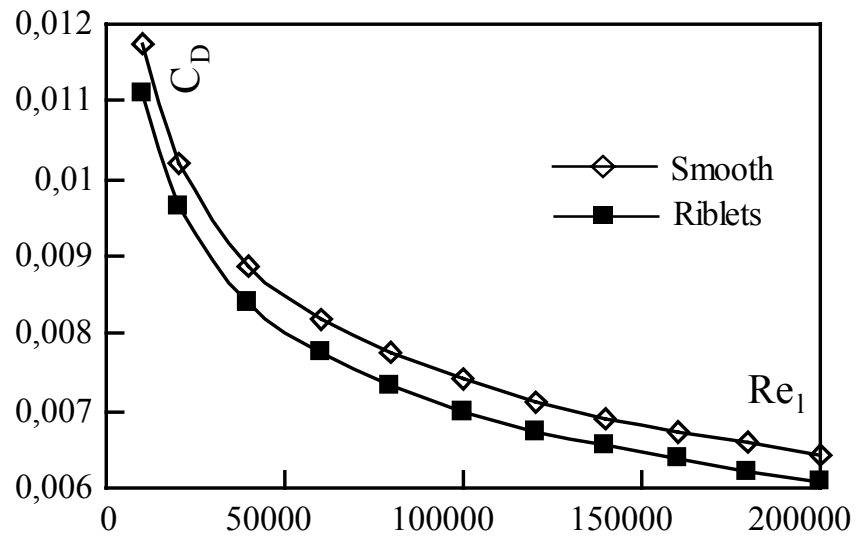

Figure 10. Variation of $C_{D}\left(R e_{1}\right)$

\section{DISCUSSION OF RESULTS}

Fig.3 describes clearly the behavior fluid flow from the wall until the boundary layer thickness, when the one seventh power equation (1) is used. All the data presented in Figs4, 5, 6 and 7 at each position (x), indicate that the logarithm laws $\mathrm{A} \log \mathrm{Y}^{+}+\mathrm{B}$, for the smooth case is different from the one for the L-shaped riblets. The same behavior was well confirmed by Wang, Lan and Chen, 2000 [18] and by Brima, Atmani and Achour, 2006 [19] for the V-riblets surfaces. The theoretical shear stress values for smooth and riblets surfaces are given in Tables 1 and 2 respectively, showing the decreasing of the shear stress along the plate for the two cases. The same behavior was observed in Tables concerning the friction velocity. It is clearly represented in Fig.8. Moreover, the $\mathrm{s}^{+}=2 \mathrm{~h}^{+}$values for the riblets shape indicate that the interval reduction is respected. Comparing the data reported in Tables 1 and 2; we can observe that the ribbed surface boundary layer thickness is thinner than that of the smooth one. The opposite behavior was observed for the laminar sub-layer thickness. Indeed, the laminar sub-layer ribbed plate thickness is greater than that of the smooth flat. This ultimately indicates a reduction in the momentum exchange between regions of low and high velocity fluid. Fig.9 describes clearly the effect of the friction coefficient. It is important just after the leading edge and start to decrease with the increase of the distance along the plate in the same direction of the flow. As, it can be observed in Fig.10, the drag coefficient decreases with the increase of Reynolds number for the smooth and riblets plates.

\section{CONCLUSIONS}

L-shaped riblets can be used as a surface modification in order to reduce the drag for a smooth flat plate. For the flow over riblets surfaces, the thickness of the viscous sub layer and the integral second constant B in the log-law are greater than those of the smooth plate. We can also observe that both the boundary layer thickness and the local skin friction are lower for the ribbed surface than that of the smooth one. Despite the fragility of this shape, therefore, the chosen case is characterized by a drag reduction property. 


\section{ACKNOWLEDGEMENTS}

The authors like to express their sincere thanks to Dr: H.C.Boisson (I.M.F.Toulouse) and Dr: E.Coustols (ONERA/DMAE Toulouse) for their kind advice and stimulating discussions.

\section{NOMENCLATURE}

$\mathrm{X}$ distance along the plate from the leading edge (m);

y vertical distance above the test plate surface $(\mathrm{m})$;

b test plate width (m);

$\ell$ test plate length $(\mathrm{m})$;

$\mathrm{h}$ riblets height $(\mathrm{m})$;

$\mathrm{S}$ riblets spacing $(\mathrm{m})$;

$\mathrm{U}_{\infty}$ free stream velocity $(\mathrm{m} / \mathrm{s})$;

$\mathrm{U}_{\mathrm{x}}$ velocity at height $\mathrm{y}$ above the plate at distance $\mathrm{x}$ from the leading edge $(\mathrm{m} / \mathrm{s})$;

$\mathrm{U}_{\tau}$ friction velocity $=\left(\tau_{\mathrm{w}} / \rho\right)^{1 / 2}(\mathrm{~m} / \mathrm{s}) ;$

$\mathrm{U}^{+}$dimensionless shear velocity $=\mathrm{U}_{\mathrm{x}} / \mathrm{U}_{\tau}$;

$\mathrm{Y}^{+}$dimensionless shear distance $=\mathrm{yU}_{\tau} / v$;

$\mathrm{S}^{+}$dimensionless riblets spacing in the law of wall coordinates $=\mathrm{sU}_{\tau} / \mathrm{v}$;

$\mathrm{h}^{+}$dimensionless riblets height in the law of wall coordinates $=\mathrm{hU}_{\tau} / \mathrm{v}$;

A, B, C constants;

$\mathrm{C}_{\mathrm{f}}$ dimensionless skin friction;

D total drag force $(\mathrm{N})$;

$\mathrm{C}_{\mathrm{D}}$ dimensionless drag coefficient;

$\mathrm{Re}_{\mathrm{x}}$ dimensionless Reynolds number at any distance $\mathrm{x}$ from the leading edge;

$\operatorname{Re}_{\ell} \quad$ dimensionless Reynolds number based on the test plate total length;

$\mathrm{Re}_{\mathrm{h}}$ dimensionless Reynolds number based on the height of the channel;

$\delta \quad$ boundary layer thickness (m);

$\delta_{\mathrm{L}} \quad$ laminar sublayer thickness (m);

$\rho \quad$ fluid density $\left(\mathrm{Kg} / \mathrm{m}^{3}\right)$;

$v \quad$ kinematic viscosity $\left(\mathrm{m}^{2} / \mathrm{s}\right)$; $\tau \quad$ shear stress $\left(\mathrm{N} / \mathrm{m}^{2}\right)$.

Subscript: $w \quad$ wall

Superscript: + dimensionless characteristics

\section{REFERENCES}

[1] Walsh, M.J and Weinstein, L.M., Drag and heat transfer on surfaces with small longitudinal fins, 1978, AIAA paper, 78-1161.

[2] Chernychov, O.B and Zayets, V.A., Some peculiarities of the structure of the skin of sharks. In Hydrodynamic Problems of Bionics (in Russian), 1970, 4, 77-83.

[3] Liu, K.N., Christodoulou, C., Reccius, O and Joseph, D.D., Drag reduction in pipes lined with riblets, AIAA Journal,1990, Vol.28, No.10, pp.1697-1699.

[4] Vukoslavecevic, P., Wallace, J.M and Balint, J.L., Viscous drag reduction using stream wise aligned riblets. AIAA Journal, 1992, 30,1119-1122.

[5] Choi, H., Moin, $P$ and Kim, J., Direct numerical simulation of turbulent flow over riblets. Journal of fluid mechanics, 1993, 255, 503-539.

[6] Benhalilou, M., Anselmet, F and Fulachier, L., Conditional Reynolds stress on a V-grooved surface.Physics of fluids, 1994, 6, 2101-2117.

[7] Djenidi, L and Antonia, R.A., Laser Doppler Anemometer measurements of turbulent boundary layer over a riblets surfaces. AIAA Journal, 1996, 34, 1007-1012.

[8] Dubief, Y., Djenidi, L and Antonia, R.A., The measurement of $\mathrm{du} / \mathrm{dy}$ in a turbulent boundary layer over a riblet surface. International Journal Heat and fluid flow, 1997, 18, 183-187.

[9] Bechert, D.W., Bruse, $\mathrm{M}$ and Hage, W., Experiments with three dimensional riblets an idealized model of shark skin. Experiments in fluids, 2000, 28, 403-412.

[10] Lee, S.J and Lee, S.H., Flow field analysis of a turbulent boundary layer over a riblets surface. Experiments in fluids, 2001, 30, 153-166.

[11] Coustols, E., Effet des parois rainurées ("riblets") sur la structure d'une couche limite turbulente. Revue française de Mécanique, 2001, 4,421-434.

[12] Viswanath, P.R., Aircraft viscous drag reduction using riblets. Progress in Aerospace Sciences, 2002, 38,571600 .

[13] Stalio, E. and Nobile, E., Direct numerical simulation of heat transfer over riblets. International Journal of Heat and Fluid Flow, 2003, 24, 356-371.

[14] Brima, A. and Atmani, R., Analyse de l'influence de la modification de la géométrie de paroi "riblets" sur la réduction de traînée. Séminaire International sur la physique énergétique SIPE'7', Université Bechar Algérie, 03-05 Octobre 2004.

[15] Janna, W.S., (3 ${ }^{\text {rd }}$ edition), Introduction to fluid mechanics (Boston, PWS publishing), 1994.

[16] Holman, J.P., ( $7^{\text {th }}$ edition), Heat transfer, New York, McGraw-Hill, 1994. 
[17] Schlichting, H., (7th edition), Boundary layer theory, New York, McGraw-Hill, 1979.

[18] Wang, J.J., Lan, S.L and Chen, G., Experimental study on the turbulent boundary layer flow over riblets surface. Fluid Dynamics Research, 2000, 27, 217-229.
[19] Brima, A., Atmani, R., and Achour, B., A Theoretical Study of Turbulent Water Flow Over Smooth and "V" Riblets Surfaces. Third international Conference on water Resources in Mediterranean Basin, WATMED3, Tripoli-Lebanon, 01-03 November 2006. 